\title{
Evaluating the sophistication of vernacular architecture to adjust to the climate
}

\author{
E. Tsianaka \\ RMJM London Ltd., Cambridge, UK
}

\begin{abstract}
Globalisation in architecture and the highly developed artificial technology of the 1950s allowed architects to design buildings without responding to the needs of the people in their climates. After the oil crisis of the 1970s, architects started referring back to local and traditional methods for inspiration to re-establish the relationship between form and climate. This paper aims to evaluate whether the vernacular architecture was sophisticated enough to offer wise and sustainable solutions to the housing needs. Taking Greek vernacular architecture as a test case, the study is based on the comparison of two architectural types, which were developed at the same time in different climates; the Cycladic type and the North-Hellenic Tower type. The white cubical houses are generally considered more picturesque and photogenic compared with the less well-known NorthHellenic loggia houses. This study shows that both types have many qualities and were developed in response to local and regional characteristics with the Tower type presenting more sophisticated answers. In addition, the paper tries to support the study of not only stylish buildings, but also less elegant and cosmopolitan houses. It is possible that many sophisticated architectural answers are hidden behind the appearance.

Keywords: Hellenic vernacular architecture, Cycladic, North-Hellenic Tower, architectural form, loggia, sahnisin, winter and summer zone.
\end{abstract}

\section{Introduction}

Vernacular architecture has attracted the imagination of many architects. It is believed that traditional wisdom and lore in buildings may still offer wisely managed, economically effective and culturally appropriate solutions to the world's housing needs [1]. However, was the vernacular architecture 

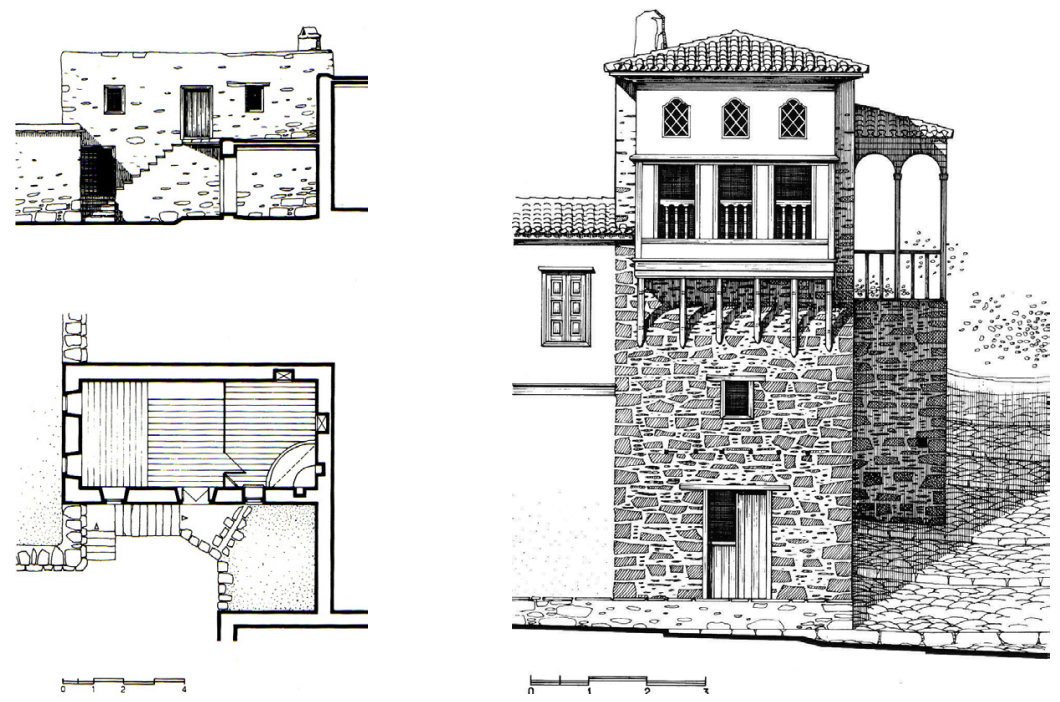

Figure 1: Cycladic house.

Figure 2: North-Hellenic Tower house.

sophisticated enough to establish a dialogue with the environment and furthermore what environmental qualities were developed? This study investigates two types of architecture of the past; the Cycladic type and the North-Hellenic type, as illustrated in figures 1 and 2. An effort to answer the afore-mentioned questions is made by examining the reaction of both types to summer and winter sun; to seasonal temperature variation, and the effect on their architectural forms. In addition, architects' search of imagination design related closely to the study of popular and elegant buildings, such as the Mediterranean vernacular cubicle houses [2, 3]. This work endeavours to combine the investigation of both popular and less known traditional buildings. The paper consists of five parts. The first two parts analyse the climate as well as the historical and social background of each location. Section four explains their architectural characteristics, while the fifth section examines their reaction to seasonal temperature variations and the effect of sun on their architectural forms, investigating the way people tried to welcome the sun in winter and shun the glare and heat in summer supported by diagrammatic illustration of shading geometry. The last part concludes the investigation.

\section{Location and climate}

\subsection{Cyclades}

The Cycladic style was developed in the South Aegean area of the Mediterranean Sea. It was mainly centred on the Cyclades, a group of twenty-three islands and most especially in Amorgos, Mykonos and Santorini. The landscape is diverse with mountains, gorges, sheer coasts, plateaus and sandy beaches. The climate is 


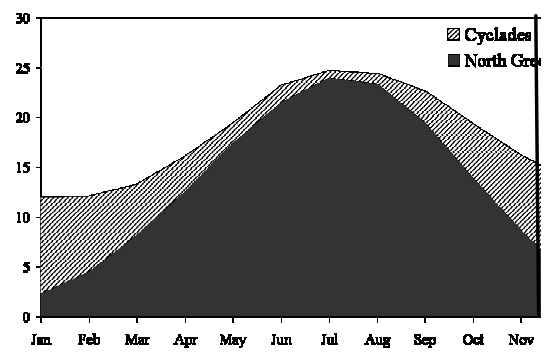

Figure 3: Comparison of $\mathrm{T}_{\mathrm{a}}$ Air Temperatures in $\left[{ }^{0} \mathrm{C}\right]$ (MeteoNorm).

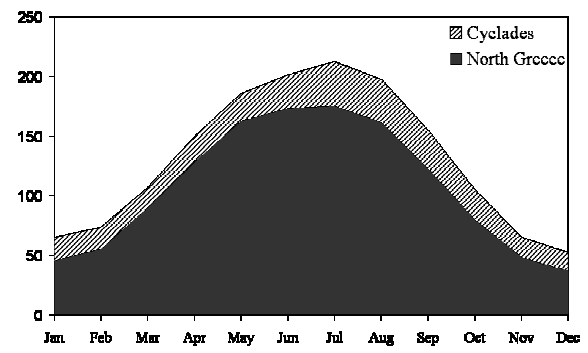

Figure 4: Comparison of Irradiations of Global Radiation horizontal in $\left[\mathrm{kWh} / \mathrm{m}^{2}\right]$ (MeteoNorm).

typically Mediterranean; it is moderate and coastal, with sunny, dry and warm summers and mild and damp winters. There is little diurnal and seasonal temperature variation and freezing temperatures are uncommon, fig. 3. The islands are subject to hot, dry winds blowing from the south and dry, cold winds blowing from the north [1]. The radiation from the sun is intense, especially in summer, fig. 4.

\subsection{North Greece}

The North-Hellenic tower style was developed in the northern Greek mainland, in Makedonia, Thessaly and East Thrace and the North Aegean. The topography has great variation: mountains, valleys and hillsides, but the usual landscape is coastal valleys surrounded by mountains. This area belongs to the continental zone, which has a climate consisting of sunny, dry and hot summers and cold, damp winters. Generally, it is a two-season climate with important diurnal and seasonal temperature variation, fig. 3. There are some local climate anomalies due to the Alps: special winds called bora in Greece [1]. The sun's radiation is high, especially in the summertime, fig. 4.

\section{Historical and social background}

\subsection{Cyclades}

The Cycladic type dates from the seventeenth century [4], when this area was a part of the Ottoman Empire. During this period, the islands suffered from continuous pirates' raids. Therefore the settlements were located inland, so as not be visible from the sea. In spite of the history of successive occupations, after the sixteenth century the majority of the population remained Greek and was Greek Orthodox [2]. The South Aegean culture was heterogeneous, with many influences from ancient Greek, Roman, and Byzantine civilizations. People used to spend more time living outside their houses than inside. They gathered in the central square, in streets, and in churches for daily discussions and social contact. 


\subsection{North Greece}

The North-Hellenic tower type dates from the sixteenth century when Greece was under Ottoman occupation. At that time, the population was mixed. Greek, Jewish and Turkish people lived together in separate ethnic-religious neighbourhoods. Heterogeneous cultures were characteristic of this time with Byzantine and Ottoman influence and many strict local rules especially for the female population. People had to spend more time in their residences, without many opportunities for entertainment and social contact. Women used to socialise in the yards or in the streets in front of their houses.

\section{Architecture}

\subsection{Cycladic architecture}

The popular Cycladic villages were developed organically in repetitive forms based on cell-like additive tradition. The houses are very close to each other and in many cases the buildings share party walls or roofs. Individual Cycladic buildings are not necessarily unique but collectively form a unique cubical urban environment famous for the inspiration derived from them, as shown in fig. 5.

Both interior and exterior spaces are simply and economically developed. The plans, rectangular shapes usually with 1:2 proportions, vary according to specific needs within the limitation of the building order. They are single or two-storey houses and include living space, sleeping rooms and kitchen area. In some cases, working room is comprised while the toilet is always out of the building. Each dwelling has a small outdoor space: an interior courtyard, a yard or a roof terrace. The Cycladic structure is masonry, contrasting with the mild local climatic conditions. Three reasons explain this choice: stone was the main local material, the islands were susceptible to earthquakes and the people preferred more permanent structures [1]. The most visible element in Cycladic architecture is the flat earthen roof (doma) used for drying products, sleeping on hot summer nights, or for social contacts, an element harmonized with the hot dry climate. The whiteness of the Mediterranean village, for both practical and symbolic reasons, is a very interesting architectural feature. The white surfaces make the streets more negotiable after dark, maintain a level of hygiene, protect against diseases, and reflect the summer heat. Moreover, they unify the settlement giving emphasis to the sense of civic pride in the community.

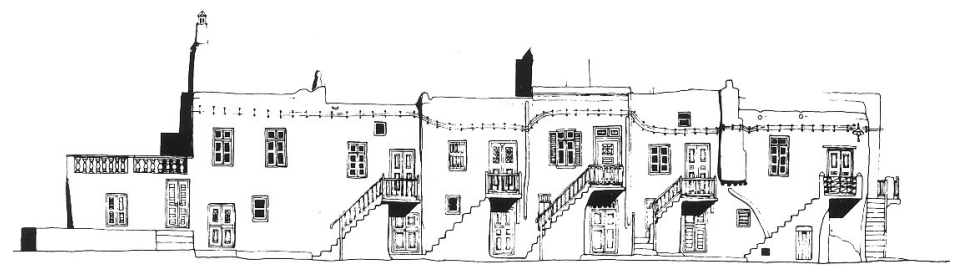

Figure 5: Settlement of Mykonos Island. 


\subsection{North-Hellenic architecture}

The North-Hellenic villages are mountainous and fortified principally because the enemies' invasions were frequent. The built-up area is typically dense and nucleated with irregular streets and with a central square. The most interesting characteristic was the division of built-up areas into ethnic-religious quarters, allowing the co-existence of these cultures. This less popular type is an evolution of Byzantine architecture, as presented in figure 6 with influences from both Western and Eastern culture [1]. This style, with more complex architectural structures and exhibiting greater skills, was reflected not only in public, but also in residential architecture [5]. They are mainly two-storey houses. The ground floor walls are usually made of local stone $60 \mathrm{~cm}$ to $65 \mathrm{~cm}$ thick, while the upper are lightweight walls $20 \mathrm{~cm}$ to $25 \mathrm{~cm}$ thick [6]. A very interesting architectural feature is the slightly inclined roof, at thirty degrees inclination, found in temperate climates with a consistently dry summer, as in northern Greece. The most notable elements in North-Hellenic architecture are the hagiati and the sahnisin, both of them controlling the level of sunlight in dwellings.

A hagiati (loggia) is a semi-enclosed space, also called doxatos. It is an efficient topological and morphological element not only of the Greek traditional dwelling, but also of the Balkan and Minor Asian dwellings. It is situated either in ground level or in upper levels. Hagiati was a multi-purpose room. Workers used to spend their time after work continuing the process of the agricultural products, women used to weave and to prepare the daily meal in open-air fireplaces.

A sahnisin (solaria) is a wood-frame extension of the main room cantilever over the street to the masonry bases. This extension could be either in the front façade of the house or on the sides. Principally, it was designed for the formal room of the home and there were no specific size dimensions. This morphological and functional architectural feature derives from Byzantine vernacular architecture and not from Ottoman architecture, as the Ottoman dwelling adapted sahnisin from Byzantine dwellings and spread it throughout the Balkans [5]. There were also social reasons for the sahnisin, as it worked as an opening to the outside world for the female population. Women hid behind the curtains of sahnisin windows, watching what was happening in the streets when it was dangerous outside. Besides this, the sahnisins were useful for cooling off in the summer days, especially when the house did not have a hagiati.
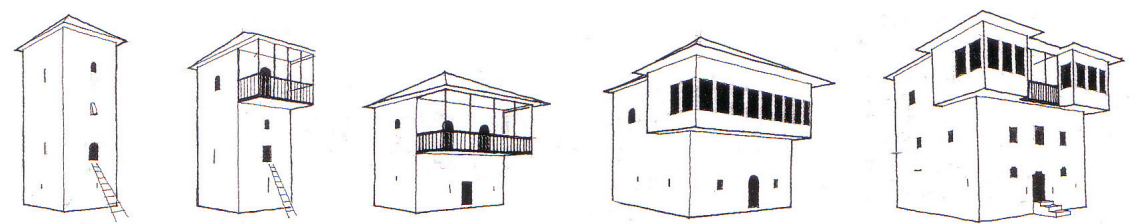

Figure 6: Evolution of North-Hellenic Tower type. 


\section{Effect of climate on architectural form}

The gradual evolution of buildings in vernacular architecture is based on the experience of many centuries and depends on the local environment and climate, as well as the social characteristics. The analysis of the climatic response of vernacular buildings is proved to be more complicated than expected. It is difficult to separate out cultural and social issues, and also technical constraints set by availability of materials, topography etc, none of which are strictly climatic. However, climate produces certain effects on architectural forms, which are easily observed [7]. The following section endeavours to identify the environmental qualities of each traditional type and to investigate their reaction to temperature variations, and winter and summer sun.

\subsection{Cycladic type: environmental qualities}

The Cycladic type embodies some environmental qualities, essentially because of the functional simplicity of the structure. On the one hand, the rectangular plan is the perfect shape for hot and dry climates and on the other hand, the space configuration is very helpful, because the multi-purpose room is usually facing the south or east. This type of architecture puts more emphasis on protection from light not only at the scale of individual buildings, but also at the urban scale. The sun's radiation is very intense, and the need for sun protection is fundamental. Moreover, people preferred to spend more time outside than inside.

Consequently, how does vernacular architecture seek to protect people from the rich and dramatic light? First of all, architecture tries to limit light in settlements by a combination of narrow and shade-inducing streets, tunnels and vaults. There are numerous examples of the previous architectural elements in Cyclades villages. Light and heat are also reflected by the annual whitewashed surfaces. Furthermore, the heavy masonry architecture provides extremely stable interior conditions that are desirable in summer [1]. In this type of vernacular architecture, some facades are completely without windows and some others have small openings for ventilation and lighting. Social areas that need sufficient light have larger windows compared to sleeping areas, which have tiny openings. An interesting feature of light management, which can be also found on the tower type, is the widening of the window sides and sill towards the interior for glare control [6].

However, there are two architectural features that the Cycladic vernacular did not adopt, which are very common in other places with the same climatic conditions. There are no shadowing-shelters over the openings and no loggia. Both are prevalent in the Mediterranean area.

\subsection{North-Hellenic tower type: environmental qualities}

The North-Hellenic tower type offers numerous methods of temperature and sun control: the separation of summer and winter zone and the use of loggia and sahnisin along with the opening size and the proper orientation. 
The main characteristic of this type is the inter-seasonal use of different spaces. The houses were divided into summer and winter zones. The winter zone was either on the lower level (stone structure) or on the upper level coexisting with the summer zone, while the summer zone was situated on the upper level (timber structure). The winter zone had a lower ceiling, fireplace and southfacing windows. The size of the openings was small and used mostly for ventilation and lighting in wintertime. Shutters were not common because the light was desirable during the short winter days. In the winter zone, the minimum internal air temperature is maintained at high levels compared to the very low ambient temperature in winter due to the high thermal inertia of the overall structure [8]. Contrary to winter zone, the summer zone had numerous large and cross-ventilating windows. The shutters were absolutely necessary in order to avoid overheating. Sometimes, this space was completely open on hot days. An interesting element of the summer room was the clerestory windows, as shown in figure 2, additional openings above the conventional windows for exploiting sun luminance. During the summer day, the large windows were usually shuttered and only the clerestory windows lighted the space.

Hagiati functioned as a shaded balcony in summer protecting the interior from overheating and a sun space in winter allowing the lower sun of winter to penetrate for solar advantage [3]. Sometimes, it was closed in winter and open in summer in order to adjust to two different environmental conditions. Consequently, it combines the advantages both of the enclosed and open space. Additionally, it was a place for socialising, especially in winter days. People gathered for discussion and lunch or dinner.

Sahnisin was created for functional reasons: the lack of sun lighting in residential buildings. The built-up area and the irregular streets did not allow direct sun lighting of the houses, so these solaria were an answer to this problem, and their name (solaria) proves their origin [5]. This space with at least two large windows and a few fanlights, positioned usually to the south or east on the upper floors, was the main summer room of the dwelling. The daylighting conditions on the upper floors are considerably better than of those on the ground floors [9]. Another problem it solved was that of the lack of space on the upper level. This extension could increase the size and orthogonality of the upper level to the main street of the settlement. As a result sahnisin also offered protection from the sun and rain to pedestrians.

\subsection{Discussion and summary}

Summing up the basic architectural characteristics and the methods developed for sun protection and temperature control of the two types, some interesting conclusions emerge. To begin with, these two Hellenic types constitute two completely different architectural approaches, even if they were both developed at the same time and are adjacent to each other. This is due to the fact that they are two architectural results that evolved from a specific social, environmental and cultural background. The different sites, the climatic variations, the use of the local materials, and the influences of other cultures entailed the formation of a particular type in a particular place. 


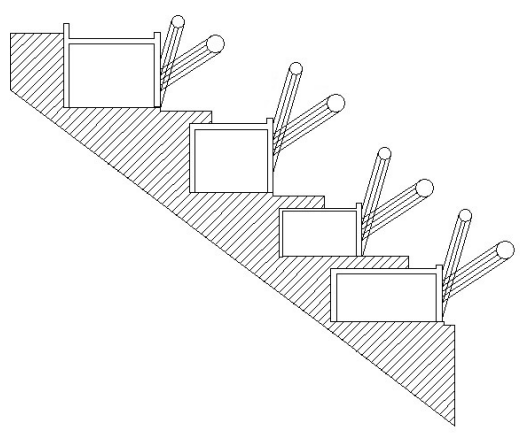

Figure 7: Shading diagram of Cyclades dwellings (Santorini example).

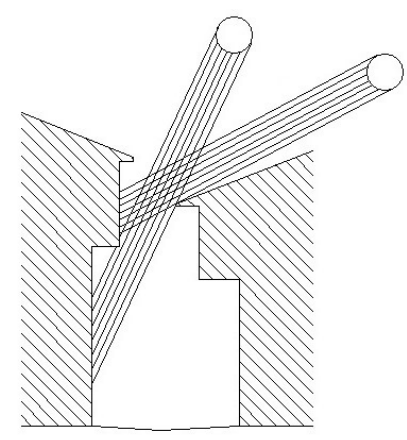

Figure 8: Shading diagram of Tower dwellings.

In both cases, the local architecture has endeavoured to establish a dialogue with the environment. Both styles make efforts to answer some of the environmental problems. In particular, the North-Hellenic Tower dwelling tries to adjust to seasonal climatic differentiations and to be more 'flexible' to temperature variation developing special architectural elements, such as hagiati and sahnisin. On the contrary, the Cycladic dwelling is more concerned with sun and summer season.

More specifically, the sahnisin in the Tower type welcomes the summer sunlight, as it is illustrated in fig. 8, while the long eaves and the shuttered windows prevent the interior from overheating. In addition, the hagiati works as a shaded balcony in hot summer days. On the other hand, the Cycladic type uses small windows to reject the sun and whitewashed surfaces to reflect the sunlight, as it is depicted in fig. 7. Both types refuse the winter sun due to the limited number and small size of openings, even if the windows are unshuttered.

Comparing the two Greek styles, the Cycladic dwellings are more picturesque and photogenic. Representative examples of this popular architecture are displayed in numerous books and magazines. These "villages in the sun" are universally known after Le Corbusier's journey to the islands of the Aegean. He discovered a public architecture influenced by trading and past occupations and he continued to draw upon this experience throughout his architectural work. The inspiration of many modern and contemporary buildings derived from Le Corbusier's projects. To the contrary, the Tower dwellings are not well-known and scenic, and did not inspire the work of many architects. Despite that, these buildings are more complicated, sophisticated and integrated. This type shows an architectural maturity in its many morphological, topological and functional elements. Specifically, the Tower style experienced adjustment to environment and climate to face social problems and to distinguish the different ethnic groups. The windows were a case in point. Shuttered windows were typical in a Hellenic residence, while unshuttered windows were popular in Ottoman dwellings. These buildings were more "flexible" and adaptable, because they could support the needs of a small society including open and closed, private and public space, 
contrary to the Cycladic cell-like buildings, which distributed within a settlement.

\section{Conclusion}

This study has shown that both types have many qualities. The vernacular architecture was sophisticated enough to answer to numerous environmental and social questions. These styles were developed in response to local and regional characteristics, as well as social and cultural requirements. In addition, it is imperative to study not only stylish buildings, but also less elegant and cosmopolitan houses. It is possible that many sophisticated architectural answers are hidden behind the appearance. Consequently, the study and analysis of vernacular houses will renew both the relationship with traditional thought and the structural rationale of the past and finally will teach us ways to confront environmental questions.

\section{References}

[1] Oliver P., Encyclopedia of Vernacular Architecture of the World, Volume 1 \& 2, Cambridge University Press, Cambridge, pp. 134-135, 144-145, 155-156, 1462-1464, 1490-1495, 1540-1551, 1997.

[2] Atrosenko V.I., M. Grundy, Mediterranean Vernacular, a Vanishing Architectural Tradition, Anness Publishing, London, pp. 14-19, 96-116, 138-140, 1991.

[3] Goldfinger M., Villages in the Sun: Mediterranean Community Architecture, London, pp.9-24, 1969.

[4] Philippides D., Greek Traditional Architecture-Cyclades, Volume 2, Melissa, Athens, 1998.

[5] Moutsopoulos N.K., Traditional Architecture of Makedonia, 15-19 ${ }^{\text {th }}$ century, Paratiritis, Thessaloniki, pp. 22-23, 30-36, 42-51, 1993.

[6] Kizis Y., Domestic Architecture in Pelion (17-19 ${ }^{\text {th }}$ c.), ETBA, Athens, pp. 523-529, 1994.

[7] Fathy H., Natural Energy and Vernacular Architecture, the University of Chicago Press, Chicago and London, 1986.

[8] Oikonomou A., Winter Thermal Comfort in $19^{\text {th }}$ century Traditional Buildings of the Town of Florina in North-Western Greece, PLEA 2005: the $22^{\text {nd }}$ Conference on Passive and Low Energy Architecture, Lebanon, 13-16 November, pp. 353-358, 2005.

[9] Oikonomou A., Daylighting in $19^{\text {th }}$ century Traditional Buildings of the Town of Florina in North-Western Greece, PLEA 2005: the 22 $2^{\text {nd }}$ Conference on Passive and Low Energy Architecture, Lebanon, 13-16 November, pp. 359-364, 2005. 